\title{
Analysis of Puncture and Prediction of Crack Fatigue in Drilling Tools
}

\author{
Guangqiao $\mathrm{Li}^{1,{ }^{*}, \text { Kejun } \mathrm{Zhai}^{2} \text {, and Zhongxi Zhu }}{ }^{3,{ }^{*}}$ \\ ${ }^{1}$ Petroleum Engineering Technology Research Institute, Sinopec Northwest Oilfield Company, 830011 Urumqi, China \\ ${ }^{2}$ Key Laboratory of Enhanced Recovery for Fracture-Cave Oil Reservoir, Sinopec, 830011 Urumqi, China \\ ${ }^{3}$ Petroleum Engineering College, Yangtze University, 430100, Wuhan, Hubei, China
}

\begin{abstract}
In recent years, the drilling technology of directional wells and large displacement wells has been widely used, which has greatly improved the reservoir development efficiency. However, the "stabbing" accidents in the drilling of the inclined section drilled frequently occur frequently. In view of the above problems, this paper uses the finite element method to take the well "003-H1", which is more serious in the drilling tool, as the research object, and deeply analyzes the cause of the "stabbing" of the drilling tool and the prediction of the crack extension period. The results show that the "piercing" of the drill pipe is mainly caused by the fatigue failure of the drill pipe. The crack on the surface of the drill pipe increases with the slope of the construction. The crack changes rapidly from elastic expansion to plastic expansion, and the fatigue life is "breaking" down, move down to create a slanting point position, which can reduce the occurrence of drill pipe "stabbing" accident.
\end{abstract}

\section{Introduction}

Drilling "stabbing" accidents often occur in deep well drilling with shallow slopes. According to statistics, since 2012, there have been many accidents such as frequent punctures and broken drills after a certain period of construction work due to shallow sloping points. These include Daqing Drilling South 3-15, China National Offshore Oil Service Z6-9-A5, Z6-9-A8 wells, of which the "stab leak" phenomenon in the 003-H1 well is the most serious [1]. According to the literature [2] and local data, it can be seen that most of the wells with the "stab leak" of the drilling tool are between 200 and $600 \mathrm{~m}$, and the maximum dogleg angle is 30 to 60 . The position of the "puncture" is roughly on the side. Drill near the dog leg (Figure 1).

\section{Drilling Tool "Puncture" Example And General Precautions}

\subsection{Failure Analysis of Drilling Tools In Well 003-H1}

In the design of the well body structure of the 003-H1 well, shallow wells were used for shallow well drilling. The position of the inclined point was $260 \mathrm{~m}$, the inclined section was $400 \sim 624 \mathrm{~m}$, and the wellbore was drilled to $2128 \mathrm{~m}$. 3 times of outer diameter of $127 \mathrm{~mm}$ drill pipe thickening transition disappearance zone piercing failure, For the third time, the large-diameter drill pipe with steel grade S135 and outer diameter of $127 \mathrm{~mm}$ was replaced.
After about one month, the drill "stab leak" phenomenon reappeared, and nine consecutive identical drill failures occurred in 14 days.

Throughout the failure characteristics of drilling tools, there are three commonalities: first, the failure parts occur in the range of $400 \sim 600 \mathrm{~mm}$ from the shoulder of the female joint, and the transition zone of the upset zone disappears; 7 of the 9 failures occur in the wellhead $300 \sim 600 \mathrm{~m}$ side track near the dog leg; the last 9 failures occurred in the $215.9 \mathrm{~mm}$ wellbore PDC drilling process, the maximum speed of $90 \mathrm{r} / \mathrm{min}$.

\subsection{General Precautions}

According to the standard of GB/T 24956-2010 "Recommended Practice of Drill String Design and Operation Limit of Oil and Gas Industry", the slanting point of the $003-\mathrm{H} 1$ is $260 \mathrm{~m}$, the dogleg angle is 60 , and the depth of the well is $2128 \mathrm{~m}$. The inclined section of Well West 003-H1 is the fatigue damage zone.

Through GB/T 24956-2010 (Figure 3), the life expectancy of the $\mathrm{S} 135$ drill pipe is $100 \%$. Therefore, the drill pipe with a calculated service life of $100 \%$ should be carefully inspected. If it is not downgraded or scrapped, it should be closely monitored as much as possible [3].

\section{Finite Element Simulation and Post Processing}

\subsection{Analysis` of The Force of The Drill Pipe}

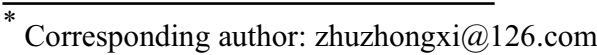


Calculation of axial stress

$$
\sigma_{\mathrm{z}}=\frac{F}{\frac{\pi}{4}\left(D^{2}-\mathrm{d}^{2}\right)} \times 10^{-6}
$$

Calculation of bending stress [4]

$$
\sigma_{\mathrm{i}}=\frac{E \cdot D \cdot C \cdot \frac{L}{2} \sqrt{\frac{F}{E I}}}{2 \operatorname{th}\left[\frac{L}{2} \sqrt{\frac{F}{E I}}\right]}
$$

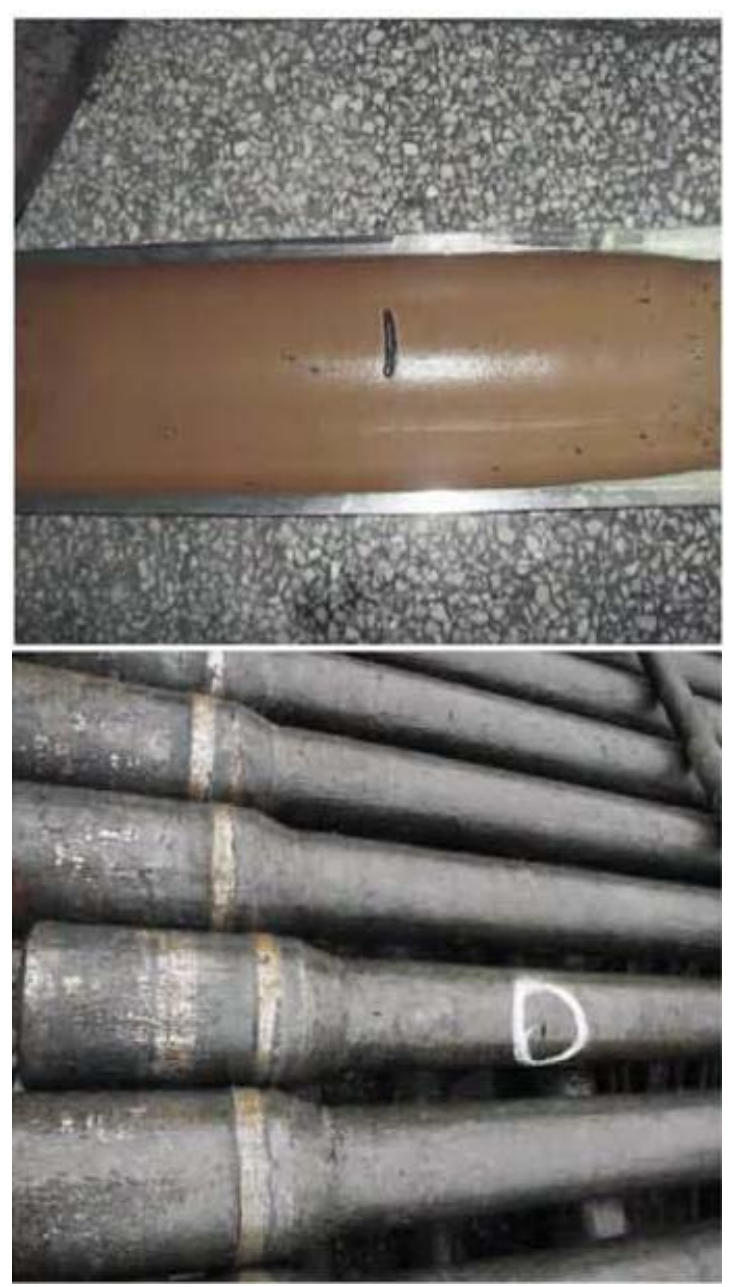

Fig 1 Photo of the failed drill in Well 003-H1

Torque calculation [5]

$$
\begin{aligned}
& N=N_{S}+N_{\mathrm{b}} \\
& M=\frac{9549\left(N_{S}+N_{\mathrm{b}}\right)}{\mathrm{n}} \\
& N_{\mathrm{s}}=4.6 C \gamma_{\mathrm{m}} \mathrm{d}_{\mathrm{c}}^{2} \operatorname{Ln} \times 10^{-7}
\end{aligned}
$$

$$
N_{\mathrm{b}}=0.0785 \mathrm{PDn} \times 10^{-3}
$$

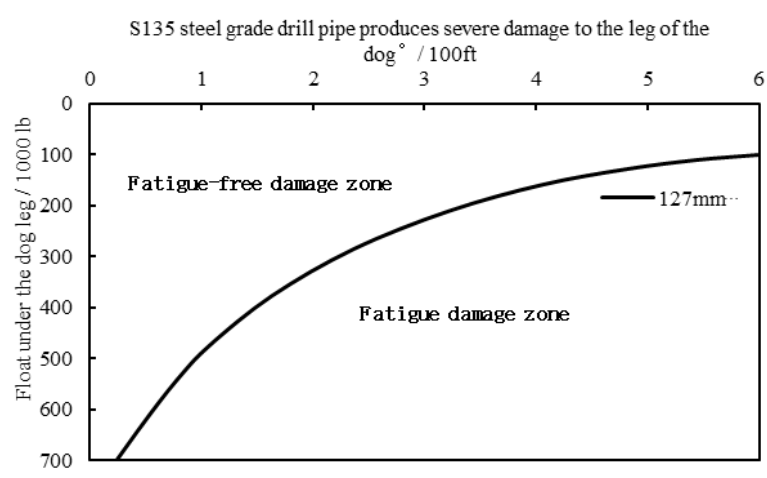

Fig 2 The limit of the dog's leg severity when the S135 steel grade drill pipe is fatigue-damaged

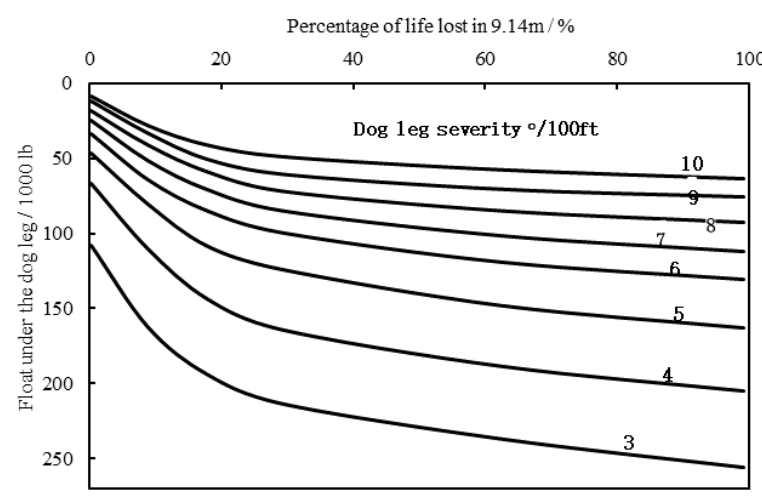

Fig 3 Fatigue damage diagram in a gradient dogleg

Through GB/T 24956-2010 (Figure 3), the life expectancy of the S135 drill pipe is $100 \%$. Therefore, the drill pipe with a calculated service life of $100 \%$ should be carefully inspected. If it is not downgraded or scrapped, it should be closely monitored as much as possible [3].

\subsection{Setting of Boundary Conditions}

The drill pipe is affected by axial stress, bending stress and torque at the shallow point. The axial and bending stresses provide open-type cracks, and the torque provides tear and slip-type cracks. According to the fracture mechanics and the actual working conditions of the well site, it is shown that most of the drill pipe fractures are open-type cracks. Therefore, the range of the female joint thread shoulder is $400-600 \mathrm{~mm}$, and the transition zone of the upset belt is the research object. The preset crack is perpendicular to the rod body, and the most commonly used elliptical crack in fracture mechanics is used as the model [6]. The drill rod is fixed at one end and the other end is subjected to tensile load and torque. With the well depth of $2128 \mathrm{~m}$, the slanting point of $260 \mathrm{~m}$ and the dogleg angle 70 as the boundary 
conditions, the axial tensile force is calculated as $133.8 \mathrm{Mpa}$ and the bending stress is $16.5 \mathrm{Mpa}$ by the formula $1 \sim 6$. The torque is $7800 \mathrm{~N} \cdot \mathrm{m}$.

The elastic modulus of the drill pipe is $2.12 \times 10^{5} \mathrm{Mpa}$ and the Poisson's ratio is 0.28 . The true stress-plastic strain relationship of the material can be checked by the literature [7]. Figure 4 shows that a is the crack depth (ellipse short semi-axis), $\mathrm{c}$ is the crack width (ellipse long semi-axis), $t$ is the drill pipe wall thickness, $A$ is the crack front edge point, B is the crack boundary point, here is convenient for description The crack shape is defined as $\gamma$ by $\mathrm{a} / \mathrm{c}$, and the crack depth ratio $\mathrm{a} / \mathrm{t}$ is defined as $\tau$.

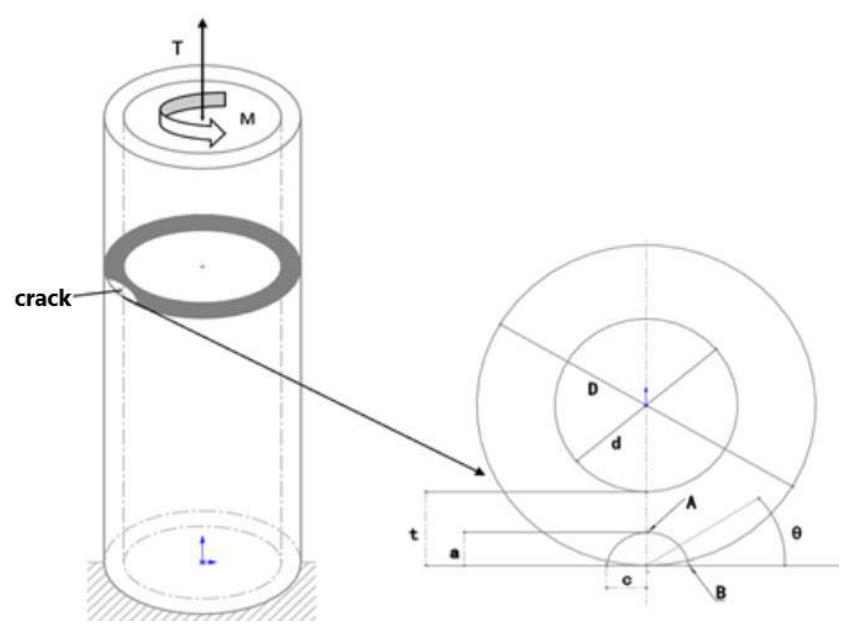

Fig 4 Mechanical model of crack in the rod

\subsection{Crack Finite Element Simulation}

When the cracked mesh is divided, the crack propagates to form an asymmetric structure due to the torque action. Therefore, it is necessary to refine the near crack segment mesh [8], where the maximum circumferential radius of the crack leading edge encryption region is 0.5 $\mathrm{mm}$, and the circumference is divided into 12 equal parts, the encryption unit layer is 8 layers. The crack position is a hexahedral mesh, and the rest is a tetrahedral mesh. The finite element simulation is performed on the divided mesh, and a set of linear elastic and elastoplastic stress maps are obtained.

Figure 5 shows that the linear elastic crack has a relatively small stress change at the leading edge of the crack, and the strain is relatively uniform at the leading edge. It is suitable for the drill pipe to work underground, and the elastoplastic crack is uneven due to the uneven distribution of the stress at the leading edge. The linear distribution promotes the accelerated propagation of cracks. Experiments have shown that the "piercing" of the drill pipe is mainly due to the formation of elastoplastic cracks in the later stage of drilling. Therefore, it is important to study the expansion mode of elastic cracks and extend the fatigue cycle time of linear elastic cracks, which will play an important role in slowing the "piercing" of drill pipes.

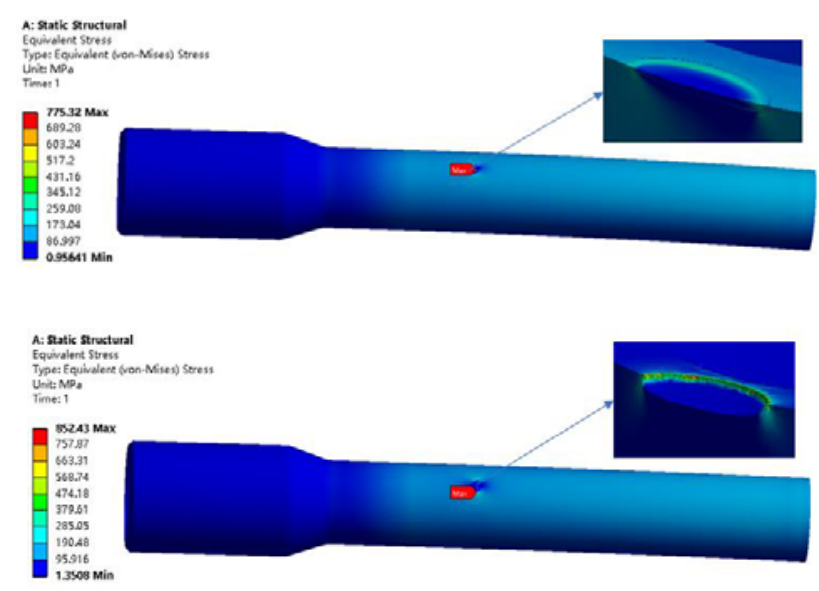

Fig 5 Linear elastic (top) and elastoplastic (lower) crack stress cloud

\subsection{Finite Element Result Processing}

Through the finite element software simulation, the stress intensity factor of the crack leading edge corresponding to different crack shape ratio $\gamma$ and crack depth ratio $\tau$ is calculated by the public description 8 .

$$
K=f \sigma \sqrt{\pi a_{c}}
$$

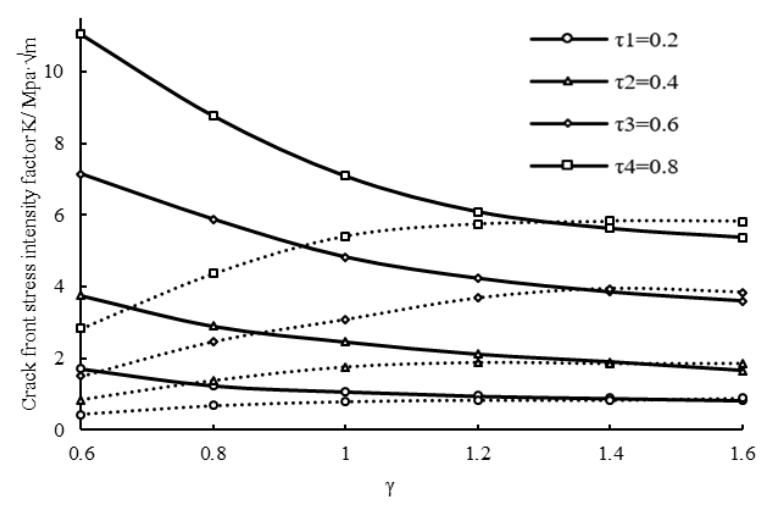

Fig 6 The solid line is the stress intensity factor at point A, and the dotted line is the stress intensity factor at point B.

As can be seen from Fig. 6, the same depth is equal to the $\tau$ condition, and the stress intensity factor corresponding to the intersection of the solid line and the broken line is the same, and the stress intensity factor of each point of the crack leading edge of the crack is the same at the combined load, that is, the diffusion rate of each point is the same. The shape ratio at this time is called the critical shape ratio [9]. The critical shape ratio at each depth ratio is recorded and further calculated by finite element software. 


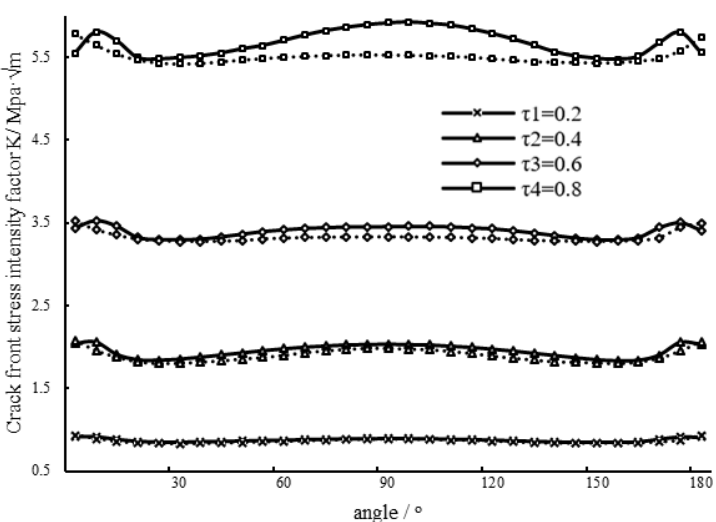

Fig 7 Effect of different $\tau$ on stress intensity factor of crack front

The solid line is the elastoplastic stress intensity factor and the dashed line is the linear elastic stress intensity factor.

The solid line in Fig. 7 shows the stress intensity factor at the crack leading edge under elastoplastic conditions, and the broken line indicates the stress intensity factor under the linear elastic condition. By studying the stress intensity corresponding to the 900 angle elasticity and plasticity, it can be obtained as the crack depth increases, at point $\mathrm{A}$. The difference in stress intensity factor continues to rise. When $\tau$ is greater than 0.6 , the plastic component exceeds $10 \%$ (Figure 8). At this moment, the elastoplastic constitutive relationship is more suitable.

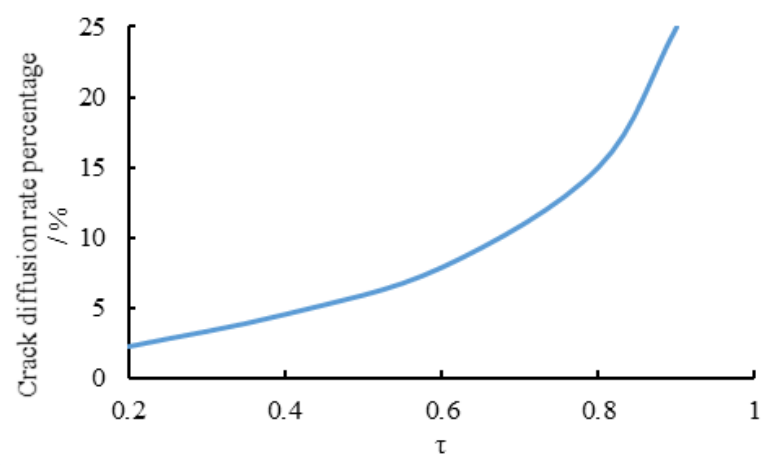

Fig 8 Effect of $\tau$ on the percentage of crack diffusion rate

\section{Conclusion}

(1) Drill pipe with fatigue loss level up to $100 \%$, the critical shape ratio of cracks in the inclined section can be calculated by finite element software, and the crack propagation period is calculated by Ncode software. The drill pipe is taken out in advance after the crack propagation reaches the high speed zone. Prevent the occurrence of "punctures".

(2) Taking the 003-H1 well as an example, the crack growth rate of the drill pipe in the vertical section is slow and the service life is long. When the drill pipe reaches the inclined section, the drill pipe is rapidly transformed into a plastic crack by the elastic crack. The fatigue cycle is "falling off", so it is important to calculate the fatigue cycle of the drill pipe at the bevel.
(3) Before the drilling tool is placed under the stratum, the crack near the transition zone of the drill pipe upset zone should be inspected and graded in time. If it is not a special case, when drilling in medium and deep wells, the depth of the inclined point should be moved as much as possible to reduce the occurrence of "stabbing" accidents.

\section{References}

1. Zhu Guoning, Xu Di. Analysis of Causes of Failure of Drilling Tools in Bohai Oilfield and Countermeasures. Petro China Chemical Industry Standards and Quality, 2018(10).

2. Zhu Quanta, Yue Yuhua, Wang Dekang, et al. Relationship between shallow point and fatigue cumulative failure of drilling tools and its enlightenment.Natural Gas Industry, 2014, 34(9): 76-83.

3. General Administration of Quality Supervision, Inspection and Quarantine, China National Standardization Administration, GB/T 24956-2010. Oil and gas industry Recommended practice for drill string design and operating limits. Beijing: China Standard Press, 2010

4. Fang Zhou. Failure Analysis of Drill Pipe. Southwest Petroleum University, 2006.

5. Shi Xiaobing, Shi Taihe. Study on failure of drill string in the lower part of curved wellbore.Journal of Southwest Petroleum University(Natural Science),2001, 23(5):54-57.

6. Zhao Guanghui, Zhao Li, Shi Jian, et al. Fracture properties of surface cracks in drill pipe joints. Chinese Journal of Applied Mechanics, 2016, 33(5): 838-844.

7. Shi Yiping, Zhou Yurong. Detailed Explanation of ABAQUS Finite Element Analysis. Mechanical Industry Press, 2006.

8. Zhao Guanghui, Zhao Li, Tang Song, et al. Fracture properties of surface cracks in thickened transition section of drill pipe.Journal of Mechanical Strength, 2017(04):177-183.

9. Wang Haozhen. Study on static and dynamic fracture characteristics of three-dimensional cracks on the surface of drill string. Southwest Petroleum University, 2014. 